\title{
Entrevista com Milton Hatoum
}

\author{
Julio Pimentel Pinto \\ Prof. Livre Docente Depto. História - USP \\ juliop@uol.com.br
}

\author{
Francine Iegelski \\ Profa. Adj. Depto. História - UFF \\ francineiegelski@hotmail.com
}

\author{
Stefania Chiarelli \\ Profa. Adj. Instituto de Letras - UFF \\ stefania.techima@uol.com.br
}

\begin{abstract}
Recebido em / Aprovado em : entrevista selecionada.
Como citar este artigo: Pinto, Julio Pimentel; Iegelski, F.; Chiarelli, S. "Entrevista com Milton Hatoum”. Intelligere, Revista de História Intelectual, São Paulo, v. 2, n. 2 [3], p. 2-10. 2016. Disponível em $<$ http://revistas.usp.br/revistaintelligere $>$. Acesso em dd $/ \mathrm{mm} /$ aaaa.
\end{abstract}

Julio Pimentel Pinto, Francine Iegelski e Stefania Chiarelli: Há um binômio que muitas vezes aparece na obra de grandes autores, dentre eles, a sua: viagem e leitura. Se possivel, desdobre um pouco essa presença, que pode se dar tanto nas figuras deslocadas culturalmente (que leem para reencontrar um lugar distante no tempo e no espaço, como o patriarca do Relato) quanto em relação a um deslocamento real — são inúmeras as viagens a que hoje um autor se habitua, para falar de sua obra, participar de encontros com o público leitor e atender a compromissos. Sabemos por outros depoimentos seus que as viagens longas e distantes já não interessam tanto. Você poderia detalhar melhor essa questão, ou seja, em que aspectos hoje a viagem interessa ao escritor?

Milton Hatoum: A viagem é um dos grandes temas da literatura, da poesia, da prosa. Alguns dos grandes romancistas do século XIX foram também grandes viajantes. Basta lembrar de escritores viajantes que falaram sobre suas viagens, de Stendhal e de sua paixão pela Itália, de Goethe, de Chateaubriand, de escritores que inauguraram o orientalismo na França. Pode-se dizer que a obra de Stendhal seria outra sem a experiência italiana. Ele, aliás, adorava a Itália e tinha mais afinidade com a cultura italiana, com a Itália, do que com a própria França, era muito crítico aos franceses. Mas penso que essa relação entre a escrita e a viagem existe desde sempre, desde a Odisseia. A descoberta de outras culturas, o contato com outras línguas, tudo isso faz parte do impulso humano de conhecer, de sair do seu lugar. Foram poucos os escritores que não viajaram. No Brasil, os dois casos clássicos são Machado de Assis e Mário de Andrade, que não precisaram viajar para escrever suas obras. Machado, sobretudo, praticamente não saiu do Rio de Janeiro. Mário de Andrade viajou pelo Brasil, foi até Quito, e essa viagem foi fundamental para escrever Macunaíma. Sem essa experiência ele também teria escrito outro livro. Eu fui um viajante desde a minha juventude. Viajante meio solitário, pois saí sozinho de Manaus, com dois amigos, aos quinze anos de idade e fui morar em Brasília, numa época muito difícil, em 1968, 1969... e depois me mudei para São Paulo, onde vivi dez anos, para então viajar novamente, dessa vez para o exterior, pois queria sair do país, fugir do regime totalitário. Minha geração não aguentava isso aqui na época da ditadura. Eu ganhei uma bolsa e morei na Espanha, morei na França. Tudo isso foi muito importante para a minha vida, para a minha experiência: as leituras que fiz enquanto viajante, as coisas que conheci, o modo de ver o Brasil, de ver minha cidade à distância, de longe, o que permite uma outra perspectiva 
das coisas. Acho que o distanciamento às vezes é necessário para se escrever. Pensando bem, vários romances escrevi distante do meu lugar. Então a viagem pode ter, além de um componente do prazer, o motivo da angústia, uma vez que há viajantes que viajam por obrigação, escritores que viajam para o exílio. O drama dos refugiados já é uma grande tragédia do nosso século. Outro exemplo seria a história dos imigrantes. Como neto de imigrantes, sei bem que a viagem para eles não significou uma experiência prazerosa. Escolher outro país para viver de forma espontânea é muito diferente de quando se é obrigado a sair de seu país e adotar uma nova pátria, uma nova língua. Então, há essas viagens compulsórias que são terríveis, são viagens do ponto de vista da tragédia: quando é preciso deixar o seu lugar, seus amigos, sua cultura, sua língua, e partir para uma aventura que é muito mais uma desventura, uma desgraça, algo muito diferente do que os prazeres que uma viagem movida pelo desejo pode suscitar. Mas um escritor não precisa necessariamente viajar. Citei os exemplos de Mário de Andrade e Machado de Assis.

J.P.P, F.I. e S.C.: José Lezama Lima, por exemplo, viajou apenas quando jovem...

Milton Hatoum: Sim, foi apenas ao México uma vez, visitar a irmã, se não me engano. Era um homem muito sedentário, muito ligado à vida insular e, no entanto, foi um dos maiores escritores da língua espanhola. Então, pode-se considerar uma outra componente, uma outra viagem, que é a da imaginação, a viagem imaginária. Uma vez mencionei que não tinha mais vontade de participar de encontros no exterior, pois estou também numa idade que... e, depois, já viajei tanto... Quando era estudante, quando estava no começo da vida profissional, morei em sete cidades e já não me lembro em quantos quartos de empregada morei na França, em quantos estúdios. Chega um momento em que você cansa e quer parar. Hoje, por exemplo, sei que não vou mais viver em Manaus, na minha cidade. Sei que quero morar aqui, em São Paulo, a cidade que bem ou mal me acolheu, onde me formei, onde me formei como leitor, onde tenho amigos. Minha família toda é daqui, o meu trabalho é aqui, então não faz mais sentido voltar para as minhas origens, mesmo porque as origens são tão confusas e difusas que posso muito bem escrever sobre o Amazonas aqui em São Paulo. Ou daqui, desde São Paulo, esse "desde" que, como dizem os espanhóis, é "de dentro", do meu sentimento da minha cidade.

Mas os poemas sobre a viagem são maravilhosos. Apollinaire escreveu um livro belíssimo, Lettre-Océan, e lembro agora de Invitation au voyage, de Baudelaire, essas são também viagens imaginárias. Como falou Borges, há poucos temas na literatura: a viagem, o amor, a morte, o tempo e, talvez para ele, o labirinto.

J.P.P, F.I. e S.C.: Antonio Tabucchi, retomando o tema pessoano do desassossego, falou que o século XX seria o século do desassossego. Ele próprio foi um viajante na geografia e na lingua, estudou o português. Diz̨ia que talvez a marca mais forte desse desassossego fosse justamente a viagem, a impossibilidade para o escritor e para o leitor de se fixar, pois o leitor também circula. Mas, para o século XXI, você falou, agora há pouco, de outro aspecto da viagem, mais terrivel, que é a busca de refúgio.

Milton Hatoum: Eu acho que o desassossego está em todos os tempos, não se limita ao século XX. Viver é perigoso, como disse Guimarães Rosa, e, ao contrário do que disse Francis Fukuyama sobre o fim da história, acho provável que seja o fim do livro dele, porque é uma besteira. Como "fim da história”? Nem "fim da história", nem "fim dos tempos". Essa é uma perspectiva muito conservadora e, por outro lado, o "fim dos tempos" é uma perspectiva muito religiosa. O "tempo" do Ocidente é linear e, ao mesmo tempo, conflui para a eternidade. 
Eu prefiro perceber o "tempo" como uma sucessão de agoras, de instantes. O prazer está nisso, no instante em que a gente vive e não em uma sequência muito linear.

J.P.P, F.I. e S.C.: Muitos leitores identificam seus romances aos livros de Raduan Nassar pela temática da imigração árabe, do exotismo de relações híbridas entre o Ocidente e o Oriente.

Mas, antes de ceder ao primeiro impulso de relacionar o que vocês dois escrevem por meio de uma identidade cultural compartilhada, podemos seguir por outra via, menos evidente. Pensamos sobretudo no trabalho que vocês dois empreendem com a linguagem, para, como diria o poeta Manoel de Barros, "escovar as palavras" e ir atrás dos clamores antigos que estariam guardados dentro das palavras.

Nessa busca pelas palavras, por uma origem da escrita, da vida, das histórias, você e Raduan tematizam problemas como a apresentação do passado, a morte, a relação com o outro, o sentimento de perda, a política, a vida de famílias imigrantes em terras brasileiras. Como você pensa a relação entre a sua obra e a do Raduan?

Milton Hatoum: Acho que o que aproxima minha ficção da obra do Raduan são algumas afinidades temáticas em relação a essa origem libanesa no Brasil e a certas leituras também. Penso que a experiência de uma família de imigrantes - seja de asiáticos, árabes, portugueses, ou mediterrânea e até dos migrantes internos do Brasil -passa pela adaptação dessa família nesse novo lugar. No caso dos imigrantes que vieram de outros países, a língua é uma das questões que marcam. Depois, tem o problema de como essa cultura é assimilada no Brasil. Como, por exemplo, a cultura árabe é assimilada, e penso aqui na cultura de um modo mais amplo, que envolve até mesmo o afeto, a culinária, o modo de ser das pessoas, de se vestir. Penso que há elementos em comum numa família em todos esses aspectos e é por isso que, às vezes, as pessoas me dizem: "me lembrei tanto dos meus avós quando li seu livro", seja no caso de Dois irmãos, seja no caso de Relato de um certo Oriente. No entanto, minha família é do Norte e essas pessoas são daqui, de São Paulo, do Rio de Janeiro, do Rio Grande do Sul. Essa identificação é possível porque há elementos comuns nessa cultura e eles, os imigrantes árabes, tentam se adaptar também de maneiras afins, de modos e maneiras afins. Acho que Raduan Nassar radicalizou muito a linguagem e, deste ponto de vista, sobretudo Lavoura arcaica é uma obra em que a prosa está integrada à poesia. Então, é como se Raduan fosse um prosadorpoeta, não poetizado no mau sentido, com laivos poéticos. Ele é um prosador-poeta porque a própria construção da frase, a sintaxe, o uso que faz das palavras têm, vamos dizer, uma forma poética. Há trechos do Lavoura arcaica que poderiam ser lidos como poesia, e isso é muito raro. É ousado e é raro na literatura. No caso brasileiro, há poucos exemplos: Guimarães Rosa, Clarice Lispector... então, minha pretensão não chegou a tanto, não quis fazer isso. Queria escrever um romance com um feitio um pouco mais clássico. Acho que são essas as afinidades e as diferenças entre minha obra e a de Raduan, embora em Relato de um certo Oriente haja um ritmo poético e mesmo uma "estranha poesia" esteja presente nessa ficção, como disse o Davi Arrigucci Jr. Isso considerando Relato de um certo Oriente, pois, no caso dos outros romances, acho que a forma de narrar é muito diferente. Quer dizer, cada romance é narrado de um jeito, de um modo peculiar, pois o romance pede - e até exige - uma posição do narrador, um tom do narrador, uma construção específica que diz respeito àquilo que o escritor quer construir. Não posso, a partir de Relato de um certo Oriente, aplicar o mesmo modelo em outros romances, não daria certo. Então Relato é diferente de Dois irmãos, apesar de alguns temas confluentes, e Dois irmãos é diferente de Cinzas do Norte, que, por sua vez, é diferente de Órfãos do Eldorado. O verdadeiro problema é encontrar a voz de cada narrador e sua relação com as personagens. $\mathrm{O}$ tema da imigração parou em Dois irmãos; a não ser num conto de $A$ cidade ilhada, chamado "A natureza ri da cultura", em que falo um pouco da imigração, nos outros romances e nos outros contos, a imigração árabe está ausente. Não digo que tenha se esgotado enquanto questão, na verdade, a imigração em si, quer dizer, o movimento, as causas da imigração não foram uma 
questão literária para mim. Os personagens não querem mais voltar para o Líbano. Há uma certa nostalgia no Relato de um certo Oriente, na matriarca [Emilie], mas, em Dois irmãos, os personagens já são imigrantes de algum modo adaptados à vida brasileira. Então, o drama é outro, é um drama familiar, com conflitos sociais, a cidade arruinada, ou em processo de ruínas.

J.P.P, F.I. e S.C.: Mesmo quando o Yakub, de Dois irmãos, volta para o Líbano é em função de conflitos familiares, e não como uma tentativa de recuperar alguma raiz perdida...

Milton Hatoum: Sim, é isso, quer dizer, o país de origem já ficou para trás. Ele existe na memória dos personagens e vai existir sempre. Você não precisa ter uma única origem. Aliás, essa é a epígrafe de Cinzas do Norte: "Eu sou donde eu nasci. Sou de outros lugares". É isso o que o Guimarães Rosa fala dos estrangeiros, eu sempre gostei muito dos estrangeiros, que estão no Grande sertão: veredas e nos contos: os chineses, os alemães, os árabes, os italianos.

J.P.P, F.I. e S.C.: Em tempos de identidades essencializadas, de nacionalismos e fundamentalismos acirrados, diante de discursos que não cansam de celebrar a diferença, mas que na prática tratam de apagá-la ou pasteurizá-la, o que pode a literatura? Ela pode mostrar que, afinal de contas, não há essa fixidez, não há essa paralisia, pois "eu sou muitos"?

Milton Hatoum: Sim... "Sou uma multidão", como diz Fernando Pessoa. Mas sempre foi assim, porque a literatura fala basicamente do outro, quer dizer, é um dos modos de ver o mundo. Para se entender e criar um microcosmo, é preciso dar vOz aos outros, é preciso se desdobrar em muitos, enquanto narrador. A imaginação - que eu considero a coisa mais importante de uma obra literária -contempla o detalhe, o mínimo, e se expande ao máximo, ela não se restringe a isso ou aquilo. Então, na medida que se inventa um narrador, se está inventando um outro que não corresponde a você mesmo. Pode ter alguma coisa do escritor, mas, basicamente, é uma construção sobre o outro, a partir da visão do outro. Esse aspecto é fundamental para quem escreve ficção, porque o narrador que está lá no livro não é o autor. Primeiro ano do curso de Letras: não confunda o narrador com o autor. Se proceder assim, nada dá certo. É como confundir um ator do cinema com a pessoa, a personagem com o ator. Então, essa construção do outro, do múltiplo - que somos nós mesmos - é importante.

Agora, sobre a questão do nacionalismo: existem nacionalismos e nacionalismos. $\mathrm{O}$ nacionalismo é importante como resistência, como fator de coesão contra a opressão, para resistir à opressão, à humilhação. Há inúmeros casos na história e, mesmo hoje, basta pensar nos palestinos, o que acontece com os palestinos, que há mais de 60 anos vivem sob ocupação militar. Esse nacionalismo palestino - que é um povo sem nação - se justifica plenamente. Agora, há também o nacionalismo de extrema direita, que exclui os outros, que bane os outros do seu entorno, que cria fronteiras rígidas e que ergue muros, como foi feito em Israel, como querem fazer nos Estados Unidos e no México, como se fez na Cortina de Ferro, em Berlim. Então, esse é o nacionalismo que exclui os outros, que exclui as diferenças. A própria Europa é um continente mestiço, não é só o Brasil que é mestiço, os europeus são mestiços, eles se esqueceram disso. Qual é a unidade da Espanha, do ponto de vista da língua, da cultura? A Espanha é uma colcha de retalhos, de godos, de árabes, de judeus, de catalães, de bascos, com todo o seu passado. A Espanha é até mesmo castelhana... Cervantes percebeu como a presença dos árabes e dos judeus na Espanha foi importantíssima, tanto que Dom Quixote é escrito por um historiador árabe, Cide Hamete Benengeli. Cervantes está falando de uma Espanha que tem oito séculos de presença árabe, então os árabes fazem parte da Espanha. A França é a mesma coisa, caso pensemos como a cultura do Ocidente está entrelaçada com a do Oriente, 
pois essas culturas não estão separadas, ao contrário, elas sempre estiveram juntas e depois houve a tentativa de separá-las. Mas toda a cultura europeia depende muito da cultura oriental e vice-versa. Isso aparece até na música, como em Franz Liszt e vários outros compositores alemães que foram para a Turquia fazer seus concertos. Há também os casos de franceses que foram para o Oriente. Então, há esse trânsito de escritores, músicos, pintores, do Ocidente para o Oriente e do Oriente para o Ocidente. Muitos pintores do século XIX foram para o norte da África, para o Oriente Próximo e para a China. Matisse tinha fascínio pelo Oriente, pelos quadros e desenhos japoneses, esse é o caso também de Delacroix, enfim, da maioria dos grandes pintores. Depois teve o encanto dos cubistas e dos vanguardistas europeus pela arte africana. Isso não pode ser escondido, é uma grande hipocrisia o Ocidente achar que fundou tudo. Ele não fundou tudo, as coisas, as culturas são mescladas, sempre foram entrelaçadas. Agora, esse nacionalismo doentio pode levar, como já está levando, a posições radicais e perigosas. A literatura desarma, tenta desarmar isso, ela quer o contrário disso. Ela é o contrário do absoluto. A literatura é o reino das incertezas e das indagações.

J.P.P, F.I. e S.C.: Há mulheres fortes e até dominadoras em sua obra, como Emilie, de Relato, e Zana, de Dois irmãos. Por outro lado, seus romances também trazem para o leitor a questão do espaço circunscrito a que essas mulheres muitas vezes estão destinadas, caso de Anastácia Socorro, Domingas e Florita, entre outras. Seus escritos desvelam facetas ambiguas dessas figuras, que transitam entre opressão, manipulação, desejos ambivalentes e a afirmação do feminino. Como é estar na pele dessas figuras tão intensas?

Milton Hatoum: Verdade, a literatura está cheia de exemplos de grandes personagens femininas escritas por homens e vice-versa. Clarice Lispector e Virginia Woolf construíram grandes personagens masculinos. Virginia construiu personagens muito patéticos, ridículos, pois na Inglaterra pós-vitoriana não podia não ser pouco ridículo. Penso que tudo isso faz parte da experiência de cada um, de cada escritor. Para a construção dos personagens acho que é fundamental a infância e o que o escritor viu e vivenciou na sua infância. Por exemplo, a Domingas, a Florita, a Zana, essas personagens femininas, a Emilie, do Relato, eu não poderia ter escrito sem ter conhecido, convivido com essas mulheres fortes na minha infância e juventude. É a partir da sua própria experiência que o escritor pensa e constrói uma personagem. Elas não são jogadas no texto ao acaso, elas são pensadas, são trabalhadas a partir do que eu quero delas, de qual é a relação dessa personagem com as outras personagens. Tudo está dentro de mim, sem essas mulheres da minha infância e juventude, e outras, da minha vida, eu não teria construído aquelas personagens. Mas, ao mesmo tempo,tenho a impressão de que essas personagens se soltaram da minha vida, elas já não são as pessoas que eu conheci, ou as pessoas com as quais convivi. Eu fiz esse esforço de dar a elas uma autonomia em relação ao romance, para que não fossem reconhecidas, mas não teria problema se fossem reconhecidas. O que importa é o que elas são no romance, como elas são no romance. É curioso, muitas leitoras me perguntam sobre o fato da narradora de Relato de um certo Oriente ser uma mulher. Posso dizer que é porque a imaginação trabalha com tudo isso, com todas as nossas experiências, e ela tem que plasmá-las numa coerência, em um conjunto coerente. Primeiro o escritor imagina a personagem, inventa a personagem e depois precisa situá-la ao longo da narrativa. Isso é o que dá mais trabalho, cada personagem tem uma presença que não é aleatória, evidentemente. Por isso se passa anos escrevendo, o trabalho do escritor é um trabalho de artesão mesmo, de marceneiro sem serra elétrica, sem máquinas, de uma marcenaria antiga, aquela que é feita à mão. O recurso ao computador não é uma garantia de que se possa escrever em pouquíssimo tempo. Bem, é verdade que há grandes exceções. Um romance extraordinário do Balzac, César Birotteau, foi escrito em dois meses, foi o último romance que ele conseguiu escrever. Romance extenso, mas que já estava sendo pensado há muitos anos. Ele escreveu e depois morreu, era noite e dia, foi uma loucura, não aguentou. Mas é que Balzac vivia disso, tinha vendido os direitos antecipados, tinha contrato com uma revista e escreveu esse romance, revisou mil vezes. Naquela época não tinha nenhuma facilidade. 
J.P.P, F.I. e S.C.: Você já disse que, quando escreveu seu primeiro romance, o Relato, sentia dificuldade de transformar em ficção as experiências que viveu nos tempos sombrios da ditadura militar. Parece que você precisou deixar o tempo passar para que a memória, nessa estreita relação que tem com o esquecimento, fosse capaz. de transformar a experiência vivida no periodo da ditadura em objeto estético, sobretudo em Cinzas do Norte.

Recentemente, em curto texto publicado pelo jornal "O Estado de São Paulo", intitulado Ruina total, Chiquinha, a personagem brasileira que vive em Paris, não pode deixar de lamentar o que ocorre no Brasil: "É verdade que esse vigarista da Câmara — o Jesus.com das contas secretas na Suiça — vai presidir as sessões do processo de impeachment da madame Rousseff? Se for verdade, será um... Diabo, não encontro a palavra em português! Voilà: descalabro. A Suprema Corte e o povo brasileiro vão permitir esse descalabro, essa ruina total?".

Você poderia falar sobre as diferentes reações que esses eventos da nossa bistória politica - os que ocorreram no passado, no regime da ditadura militar, e os que ocorrem hoje — provocam na sua atividade literária de romancista e cronista?

Milton Hatoum: Vamos dizer que essa ruptura institucional, todo esse processo que culminou no impeachment foi traumático para uma parte da população, sobretudo para a esquerda brasileira. Agora, eu tento manter um ritmo de trabalho, mesmo durante esse processo. É claro que é muito deprimente tudo isso e que talvez a energia em tempos mais amenos, de normalidade, fosse maior. Eu acho que me esforço mais, gasto mais energia física e mental para trabalhar nesses últimos meses do que em um período normal da vida brasileira. No entanto, não consigo abandonar o meu trabalho literário, porque, às vezes,se paro de escrever, se cria uma espécie de zona fria na imaginação, na própria narrativa; é preciso estar muito ligado no universo ficcional, nos conflitos, na trama, nos personagens. Mas, por outro lado, toda essa desfaçatez do Congresso, tudo isso também tem um lado positivo porque desmascara todo o sistema. É curioso: eu fiz vários paralelos com a minha vivência em Brasília, quando eu era jovem, quase um garoto, dos 15 aos 18 anos. Eu me lembrava das coisas, dos amigos que estudavam no meu colégio, um colégio de aplicação, colégio de elite. Os que vinham de fora tinham que fazer exame, um mini-vestibular para entrar, os filhos dos políticos e dos ministros, não, eles simplesmente entravam. Eu me lembro que alguns colegas chegavam em carro oficial e que alguns deles eram contra a ditadura e seus pais trabalhavam no governo e para a ditadura. Lembro de uma amiga que fez uma passeata na casa dela, uma cena que eu incorporei no meu romance. Ela estava tão inconformada com o pai, com o país e com o pai, que ela fez uma passeata na península dos ministros, com faixas e tudo. Aquilo foi uma coisa incrível! Então, essa desfaçatez vem de muito longe. Não houve traição, na verdade. É que o PT não percebeu que não se pode confiar nem nos seus patifes do partido, pois eles também têm patifes que tinham que ter sido expulsos do partido, nem nesse pessoal que sempre fez política dessa maneira. O Partido Socialista Brasileiro, que já teve nas suas filas, nos anos 1940, Antônio Cândido e José Lins do Rêgo, virou essa vergonha, esse partido que não tem nenhuma diferença mais com o PR, o Partido Social Cristão, são partidos de aluguel, portanto não vai mudar nada, ao contrário, vai piorar. Eu procuro intervir de um modo mais ou menos literário, mais ou menos sutil nas minhas crônicas. Por exemplo, não pude calar diante da declaração fascista do Bolsonaro [que dedicou seu voto a favor do impeachment ao coronel Brilhante Ustra, um dos torturadores da ditadura militar]. Então tive que falar disso, pois não se pode calar sobre isso, você pode e deve criticar o PT por ter feito coisas condenáveis e erradas, mas você tem que falar com muita veemência contra o fascismo, porque aí já extrapola tudo o que há de humanidade. Perdemos a humanidade se ficarmos calados diante de uma impostura tão grande. Então, sinceramente, eu não esperava ver alguém louvar a tortura e o mais assustador é que ele tem $8 \%$ nas pesquisas, muito mais do que políticos que têm uma carreira de 40 anos de vida pública. Mas isso mostra também o quão conservador é o país, 
desde sua origem, sua estrutura, sua formação, aquilo que o Graciliano Ramos chamava, com ironia, de "o pequenino fascismo tupiniquim", quando foi preso um pouco antes do golpe de Getúlio Vargas. Esse conservadorismo está latente em uma parte da sociedade brasileira, como o riso dos deputados, o deboche desses pulhas, que o cercavam quando ele [Bolsonaro] louvou a tortura. Penso que alguma coisa tem que acontecer pela via jurídica e que a população devia se manifestar, como já está se manifestando, com pedidos de cassação, protestos nas ruas. O que me surpreende é um certo silêncio cúmplice de alguns partidos, partidos da Social Democracia, estranho isso. Então, em uma certa perspectiva, o escritor, a princípio, não deve ser leal nem à religião e nem a partidos. O escritor é basicamente um solitário, um intelectual que não se sente disposto quando não se sente livre para criticar aquilo que está errado - que ele acha que está errado - e, assim, acaba se tornando um solitário. Essa foi a posição do Edward Said, quando escreveu Representações do intelectual. Quando ele criticou a corrupção na OLP, a antiga Organização para Libertação da Palestina, criticou o Yasser Arafat, foi completamente isolado pela OLP. No entanto, Said é o maior intelectual palestino. O pensamento dele, as posições dele, a crítica literária que escreveu, filosófica, penso que tudo isso faz de Said um dos maiores intelectuais do Ocidente e do Oriente. Mas ele viu tanta corrupção e desmando na OLP que não pôde ficar calado. Certamente foi positivo para a própria OLP a postura dele, pois criou alternativas, fora da OLP, ou dentro da OLP. Então, eu vejo tudo isso com muita preocupação, acho que uma parte da sociedade está estarrecida porque Bolsonaro defende coisas que nos tornam menos humanos e isso está acima de partidos, acima de disputas ideológicas. Isso toca a nossa humanidade, fere a humanidade da gente.

J.P.P, F.I. e S.C.: E a crônica é o espaço da intervenção imediata, então?

Milton Hatoum: Geralmente é. Às vezes se refere a uma memória, às vezes fala de coisas distantes, mas nesse momento, muito dramático, é difícil falar da minha infância. A imprensa deveria falar também, a grande imprensa não deveria esquecer que vários jornalistas foram assassinados e torturados por esses Senhores que o Bolsonaro citou. O Vladimir Herzog é um deles, e tantos outros no Nordeste, uns cinco pelo menos, um jornalista do Ceará que foi torturado barbaramente. Isso está no livro que o Estadão publicou com o relato de seus próprios jornalistas que foram torturados naquela época. As redações foram invadidas, os jornalistas não podem calar agora só porque são contra a Dilma. Que jornalismo é esse? Que coisa mais condenável, nem os jornalistas, nem os intelectuais, nem os professores podem se calar, acho que as pessoas têm que se posicionar contra isso.

J.P.P, F.I. e S.C.: Na sua obra, parece que as dimensões do passado e do presente surgem com mais força, talvez. por serem os lugares de fundação da memória e da experiência. Geralmente são nas obras utópicas e distópicas que of futuro se apresenta como a dimensão temporal preponderante. Você poderia falar sobre o papel que o futuro desempenha — se é que desempenha — na construção das suas histórias, no impeto de seus personagens e nas ideias que seus textos comunicam?

Milton Hatoum: Na verdade, é difícil pensar no futuro sem entender o passado e o romance fala basicamente sobre o passado, ele é uma reconstrução de um passado que é conduzida pelo presente. O presente e o futuro são pensados a partir da observação de uma ruína, de um modo quase alegórico. É uma busca para entender o que aquela ruína significa simbolicamente para o passado, qual significado pode ter no presente e, eventualmente, no futuro. No caso da literatura, dos livros que escrevi, para mim a única coisa mais ou menos clara em relação a algum tipo de visão, de perspectiva, é o próprio ato de escrever. Os meus livros terminam com a escrita. O narrador de Dois irmãos, por exemplo, está escrevendo na sua solidão, nos fundos 
da casa, passando a limpo o passado. Mas, ao mesmo tempo, aquilo pode se projetar no livro que se está escrevendo, na memória do que se está escrevendo, pode ter alguma repercussão perspectiva no futuro. Na medida que se entende como a cidade foi destruída, é possível pensar a cidade a partir da sua destruição, do conhecimento dessas ruínas. Falar para o futuro de um modo muito explícito vira uma narrativa meio científica, como é o 1984, do George Orwell. Como podemos ver o mundo daqui 50 ou 100 anos? O Borges tem uma frase interessante que diz: "eu não posso imaginar como será a literatura no ano 2000 porque eu não conheço o leitor do ano 2000". O leitor está implicado nessa literatura e nessa leitura do presente e do futuro também. Como o leitor, daqui a 50 anos, lerá Crime e Castigo, de Dostoiévski? Haverá ainda leitura de Crime e Castigo? Eu penso que sim, certamente os grandes clássicos serão os livros que serão lidos e, enquanto houver um leitor, haverá literatura. Mas, muito menos do que falar do futuro - que pertence ao horizonte da utopia e dos nossos sonhos -, eu preferi explorar o passado como matéria literária para abrir portas para o futuro. Aquele fim de Vidas Secas, do Graciliano Ramos, em que a família de retirantes se dirige para o Sul, é tão bonito porque fala que o futuro não é só a tentativa de viver melhor; pouco antes, na sequência final, o personagem Fabiano fala da educação que os filhos poderiam ter na cidade grande. Ele está preocupado com o futuro dos filhos, que passa pela educação, e, por isso, o romance é tão poderoso. Esse livro certamente os nobres deputados não leram. Eles não leram. Eu não sei o que eles leem, nem sei se eles leem. Devem ler os bestsellers da $V$ eja, esse lixo imposto pelo mercado. Mas alguns no Nordeste certamente leram e leram bem. O problema é que a maioria é muito grosseira, não sei qual é a formação desses Senhores e dessas Senhoras. Enfim, é muito poderosa essa parte final de Vidas Secas porque fala do presente, mas também está apontando para o futuro.

J.P.P, F.I. e S.C.: Você falou do Dostoiévski. Tem uma entrevista do Carlo Ginz̧burg, historiador italiano, para uma brasileira, Maria Lúcia Pallares-Burke. Num dado momento, ela pergunta: "que conselho você daria para os jovens bistoriadores?". O Ginzburg é meio reticente, mas acaba por dizer algo assim: conversando, anos atrás, com meu amigo Adriano Sofri, eu falei uma coisa que não sei se teria coragem de repetir hoje, porque não gostaria de ser confundido com esses historiadores que dizem que fição e história são a mesma coisa, mas,vá lá, vou dizer: leiam romances, leiam romances porque eles provocam no seu leitor uma imaginação moral; quem leu Crime e Castigo na adolescência passa o resto da vida andando com o espectro do Raskolnikov às suas costas, não consegue mais se libertar dele.

Há pouco, quando você respondia outra questão, falou que não pretende imaginar o mundo futuro na sua ficção, que fala do passado porque ele ajuda a pensar o futuro. Essa ideia parece se aproximar justamente do que Ginzburg falou sobre a imaginação moral. Os leitores de seus livros vão ser acompanhados pela Emilie, pela Zana, pelo Omar, por todos eles...

Milton Hatoum: Eu lembro de uma afirmação de um grande historiador francês, não lembro exatamente quem é, um desses grandes historiadores da Nova História, que disse em uma entrevista: "A verdade da história não é a verdade da literatura porque a verdade da literatura passa pela imaginação, pela fantasia, e nós, historiadores, não podemos fantasiar o tempo todo, nós temos algum compromisso com os documentos, com a pesquisa histórica". Num romance, você pode ter situações anacrônicas, por necessidade da trama. Isso não vai perturbar a história, o que seria estranho para um historiador, mas não para um ficcionista. Quando a história entra num romance, o leitor fica fascinado porque está lendo uma ficção, está entrando num mundo que foi construído, que foi imaginado, um mundo de paixões, de traições, de conflitos sociais, de conflitos históricos. São as guerras napoleônicas na obra de Stendhal, assim como o delírio de Raskolnikov, personagem de Crime e castigo, que quer ser Napoleão, no começo do livro. Então, penso que Ginzburg tem razão. Os grandes historiadores e também os grandes sociólogos, cientistas políticos, leram romances. Freud também. Eu, por exemplo, 
não conheço nenhuma análise mais fina, mais profunda da alma humana do que a obra de Marcel Proust. E, no entanto, o que ele escreveu foi um romance: Em busca do tempo perdido. Proust apreende um personagem e o estuda de mil maneiras, por vários âmbitos, sua grandeza, sua mesquinhez, sua loucura. Os detalhes da narrativa que são aparentemente desinteressantes, ou aparentemente gratuitos, reaparecem duzentas páginas depois com uma força impressionante e, assim, o leitor percebe que esse detalhe tinha uma razão de ser desde antes. Penso que é disso que se trata a imaginação moral. Na Europa, de um modo geral, o ensino da língua e da literatura é muito privilegiado. Não é preciso ser um grande observador para perceber que uma faixa considerável da classe média brasileira não tem acesso, não está interessada na literatura. Que tipo de formação educacional eles tiveram? Pensa um pouco: alguém que tenha lido Os sertões, ou Vidas secas, não pode erguer uma faixa escrita "Somos milhões de Cunha". A pessoa que faz isso, a pessoa que se cala diante dessa barbaridade, diante da desfaçatez, é uma pessoa que, de fato, não tem a mínima compreensão do Brasil. A compreensão do seu país passa também pela leitura da ficção e da poesia. A leitura da história exige essa imaginação moral que vocês mencionaram. O Ginzburg é um grande historiador, atento aos detalhes e aos indícios que lhe interessam tanto e, diga-se de passagem, esse é um traço muito literário na obra dele. Ginzburg é filho de uma grande escritora italiana, uma das maiores. Natalia Ginzburg, uma das minhas autoras preferidas. 